\title{
Pengaruh Point Vuforia Object Scanner Terhadap Karakteristik 3D Object untuk Menampilkan Informasi Berbasis Augmented Reality
}

\author{
Putri Mandarani, Agung Putra Wilis, Ganda Yoga Swara*
}

Fakultas Teknik, Program Studi Teknik Informatika, Institut Teknologi Padang, Padang, Indonesia Email: ${ }^{1}$ pmandarani2@gmail.com, ${ }^{2}$ agungpw97@gmail.com, ${ }^{3, *}$ gandayogaswara@itp.ac.id Submitted: 29/07/2021; Accepted: 24/08/2021; Published: 31/08/2021

\begin{abstract}
Abstrak-Aplikasi Augmented Reality (AR) menjadi salah satu tren aplikasi mobile saat ini. Kemampuannya menampilkan informasi seolah-olah membuat pengguna menyatu dengan informasi yang diberikan. Keistimewaan aplikasi ada pada marker. Salah satu marker yang banyak diminati dikenal dengan istilah markerless, seperti $3 D$ Object Tracking. Dalam membuat aplikasi AR berbasis $3 D$ object ini, harus melewati tahap dimana suatu objek nyata diambil titik-titiknya atau yang dikenal dengan istilah point untuk dijadikan marker. Aplikasi yang digunakan pada tahap pembuatan marker ini dikenal dengan vuforia object scanner. Dari pengalaman membuat aplikasi AR, ditemukan kondisi dimana marker dengan jumlah poin yang banyak tidak mampu menampilkan informasi dengan baik, jumlah poin yang sedikit mampu menampilkan nformasi dengan baik dan adakalnya kedua kondisi tersebut berkebalikan atau sebanding, yaitu banyak poin menjadikan marker baik dan sedikit poin menjadikan marker tidak baik. Kondisi yang tidak konsisten tersebut menjadi permasalahan dalam penelitian ini. Hasil pengujian didapatkan bahwa poin tidak berpengaruh terhadap kemampuan marker dalam menampilkan informasi, tetapi dipengaruhi oleh karakteristik dari objek yang dijadikan marker tersebut. Pengujian yang dilakukan terhadap objek yang dipilih secara random menghasilkan 2 parameter yang akan diuji pada penelitian ini, yaitu tekstur dan pola objek. Marker dengan kualitas yang baik untuk dijadikan marker objek 3D adalah marker dengan tekstur yang keras, dengan posisi sudut pendeteksian $90^{\circ}$ dan $135^{\circ}$ dan dengan pola yang teratur.
\end{abstract}

Kata Kunci: Augmented Reality; Vuforia Object Scanner; Markerless; 3D Object Tracking; Android

\begin{abstract}
Augmented Reality (AR) applications are one of the current mobile app trends. Its ability to display information as if to make the user merge with the information provided. The specialty of the application is in the marker. One marker that is in great demand is known as markerless, such as 3D Object Tracking. In making this 3D Object-based AR application, one must pass a stage where a real object is taken at points or known as points to be used as markers. The application used at this stage of making markers is known as the vuforia object scanner. From the experience of making AR applications, it was found conditions where markers with a large number of points were not able to display information properly, a small number of points were able to display information well and sometimes the two conditions were opposite or comparable, i.e. a lot of points makes a good marker and a few points make a bad marker. This inconsistent condition becomes a problem in this study. The test results show that the points do not affect the marker's ability to display information, but are influenced by the characteristics of the object used as the marker. Tests conducted on randomly selected objects resulted in 2 parameters to be tested in this study, namely the texture and pattern of the object. Markers with good quality to be used as markers for 3D objects are markers with a hard texture, with a detection angle of $90^{\circ}$ and $135^{\circ}$ and with a regular pattern.
\end{abstract}

Keywords: Augmented Reality; Vuforia Object Scanner; Markerless; 3D Object Tracking; Android

\section{PENDAHULUAN}

Augmented Reality (AR) merupakan salah satu teknologi tren saat ini yang dapat menggabungkan objek dunia maya ke dalam dunia nyata [1]. AR terdiri dari 2 marker yaitu marker based tracking dan markerless. Pengujian [2] yang membandingkan dua marker tersebut, menunjukkan objek 3D dapat ditampilkan dengan baik pada aplikasi AR yang menggunakan markerless. Dari segi penyampaian informasi, $3 D$ object paling banyak diminati karena mampu menampilkan informasi yang jelas dan interaktif [3], namun dari segi pendeteksiannya marker ini masih terkendala dengan karakteristik objek yang dijadikan marker [4]. Objek 3D yang rumit masih sulit untuk dideteksi [5], [6]. Namun hal tersebut tidak menjadi penghambat bagi pengembang aplikasi AR. Seperti di bidang pendidikan, konsep rancangan AR yang menyediakan fitur visualisasi interaktif memberikan kontribusi dalam proses pembelajaran [7], [8], [9]. Aplikasi yang dihasilkan lebih menarik dibandingkan dengan membaca buku yang tebal dan tidak dapat menampilkan informasi secara visual. Untuk itu perlu dilakukan terus ujicoba untuk melihat faktor-faktor yang mempengaruhi pelacakan dan kemunculan suatu informasi menggunakan objek 3D. Dalam membangun sebuah aplikasi AR dibutuhkan tools yang mendukung pengembangan aplikasi yang berbasis mobile ini. Banyak tools yang dapat digunakan, ada yang berbayar maupun gratis. Secara rancangan dan fungsi, vuforia dan unity 3D memberikan kenyamanan bagi para pengembang AR [10].

Penelitian ini membahas terkait teknologi tracking atau pelacakan menggunakan metode AR dan identifikasi markerless. Plugin pendukung yang menyediakan fitur object recognition dalam pembuatan aplikasi AR yaitu vuforia Software Development Kit (SDK). Untuk menjalankan plugin ini digunakan software Unity 3D yang memiliki kerangka kerja yang lengkap [11]. Aplikasi yang dibangun menggunaan 3D sebagai objek tracking, dengan kendala yang sering ditemui yaitu ketidakmampuan marker menampilkan objek 3D dan video. Konsepnya, vuforia object scanner mengambil titik pada objek yang ingin dijadikan marker, namun yang ditemui saat rancangan aplikasi, jumlah poin yang banyak saat menggunakan vuforia object scanner tidak sepenuhnya mampu menampilkan informasi yang diharapkan. Dan sebaliknya, poin yang sedikit ternyata mampu menampilkan 
Journal of Computer System and Informatics (JoSYC)

Volume 2, No. 4, August 2021, Page 304-309

ISSN 2714-8912 (media online)

ISSN 2714-7150 (media cetak)

DOI 10.47065/josyc.v2i4.826

informasi dengan baik. Tujuan dari penelitian ini adalah untuk melihat pengaruh poin vuforia object scanner terhadap objek 3D yang dijadikan marker. Pengalaman dalam membangun sebuah aplikasi AR dengan 3D object tracking menjadi batasan masalah penelitian ini dengan memilih 2 parameter yang diuji, yaitu tekstur dan pola objek.

\section{METODOLOGI PENELITIAN}

Pada penelitian ini dilakukan pengamatan terhadap jumlah poin yang didapat pada vuforia object scanner ketika kamera diarahkan ke objek yang akan dijadikan sebagai marker, proses ini merupakan bagian dari langkah membuat sebuah marker. Dalam proses tersebut ditemukan bahwa, objek dengan jumah poin yang banyak tidak mampu menampilkan informasi dengan baik, dan objek dengan jumlah poin yang sedikit ternyata mampu menampilkan informasi dengan baik. Dua kondisi tersebut menjadi acuan dilakukannya penelitian ini, dengan tahapan seperti gambar 1 .

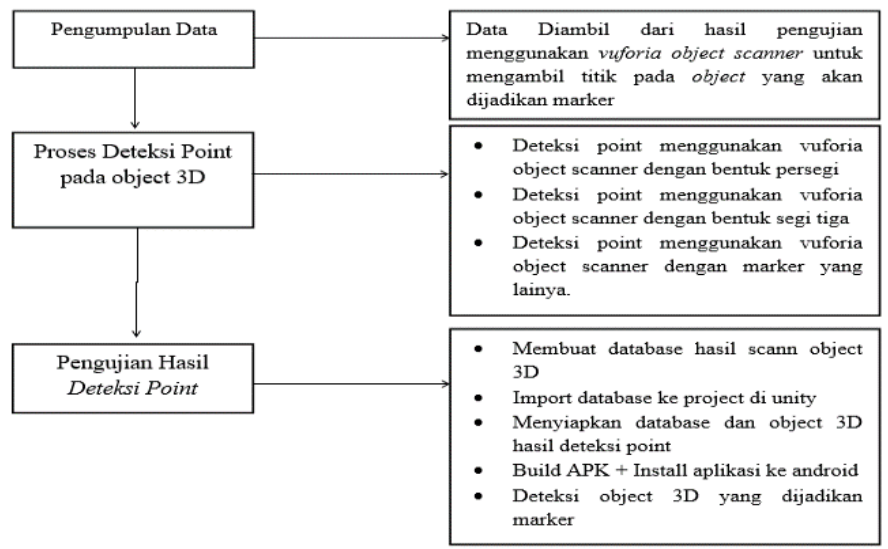

Gambar 1. Tahapan Penelitian

Untuk dapat melakukan perancangan dan pengujian sesuai dengan tahapan pada gambar 1, diperlukan perangkat pendukung, baik hardware maupun software dengan spesifikasi yang ada pada tabel 1.

Tabel 1. Perangkat pendukung

\begin{tabular}{lll}
\hline \multicolumn{1}{c}{ Hardware } & \multicolumn{1}{c}{ Software } \\
\hline a. Laptop procesor minimal Core i3 & a. & Sistem Operasi Windows 10 \\
b. Memori 4 GB (RAM) & b. Microsoft Office World 2013 \\
c. 500 GB (SATA) HDD & c. Unity 3D v.2018.2.13f1 \\
d. Smartphone Asus Zenfone Max Pro M1 & d. Vuforia object scanner \\
\hline
\end{tabular}

\subsection{Metode Pengumpulan Data}

Pada penelitian ini penulis menyiapkan sampel objek 3D menggunakan vuforia object scanner untuk mendapatkan jumlah poin yang menjadi tolak ukur objek 3D yang nantinya dapat dijadikan sebuah marker. Selanjutnya poin dari masing-masing objek 3D akan dianalisis sesuai bentuk dari object 3D yang dijadikan marker, berikutnya hasil objek 3D yang sudah dilakukakan pengambilan poin tersebut akan dilakukan percobaan pendeteksian apakah marker dapat menampilkan informasi dengan baik.

\subsection{Sampel Marker}

Sampel yang penulis gunakan pada penelitian ini adalah objek 3D dengan berbagai bentuk dan berbagai jenis, yang akan dilakukan perbandingan untuk melihat bentuk objek 3D yang seperti apa yang menjadi karakteristik yang baik untuk dijadikan marker objek 3D, dan menjadi rekomendasi yang baik untuk menentukan objek 3D yang akan digunakan nantinya.

Tabel 2. Sample Objek 3D

\begin{tabular}{|c|c|c|c|c|c|}
\hline No. & Sampel & Karakteristik & $\begin{array}{c}\text { Poin } \\
\text { Scanner }\end{array}$ & $\begin{array}{l}\text { Size } \\
(\mathrm{MB})\end{array}$ & $\begin{array}{l}\text { Hasil } \\
\text { Deteksi } \\
\text { Scanner }\end{array}$ \\
\hline 1. & e & $\begin{array}{l}\text { Objek pada gambar sampel tersebut memiliki } \\
\text { bentuk persegi dengan bahan yang tebuat dari kayu } \\
\text { dan memiliki satu warna. }\end{array}$ & 67 & 29,8 & - \\
\hline
\end{tabular}




\begin{tabular}{|c|c|c|c|c|c|}
\hline No. & Sampel & Karakteristik & $\begin{array}{c}\text { Poin } \\
\text { Scanner }\end{array}$ & $\begin{array}{c}\text { Size } \\
(\mathrm{MB})\end{array}$ & $\begin{array}{c}\text { Hasil } \\
\text { Deteksi } \\
\text { Scanner }\end{array}$ \\
\hline 2. & & $\begin{array}{l}\text { Objek pada gambar sampel tersebut memiliki } \\
\text { bentuk segi tiga, dengan bahan terbuat dari kayu } \\
\text { dan memliki } 1 \text { warna }\end{array}$ & 116 & 31,3 & 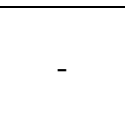 \\
\hline 3. & & $\begin{array}{l}\text { Objek pada gambar sampel tersebut memiliki } \\
\text { bentuk lingkaran, dengan bahan yang terbuat dari } \\
\text { kayu dan hanya memiliki satu warna. }\end{array}$ & 159 & 26,9 & $\sqrt{ }$ \\
\hline 4. & & $\begin{array}{l}\text { Objek pada gambar sampel tersebut memiliki } \\
\text { bentuk bintang dengan bahan yang terbuat dari } \\
\text { kayu dan hanya memiliki satu warna. }\end{array}$ & 180 & 29,4 & - \\
\hline 5. & & $\begin{array}{l}\text { Objek pada gambar sampel tersebut memiliki } \\
\text { bentuk bunga, dengan bahan yang terbuat dari } \\
\text { kayu dan hanya memiliki satu warna. }\end{array}$ & 209 & 25,2 & - \\
\hline 6. & & $\begin{array}{l}\text { Objek pada gambar sampel tersebut adalah pin } \\
\text { dengan bentuk lingkaran dengan bahan yang } \\
\text { terbuat dari plastik dan memiliki kombinasi warna } \\
\text { dan motif yang bervariasi. }\end{array}$ & 133 & 23,8 & $\sqrt{ }$ \\
\hline 7. & & $\begin{array}{l}\text { Objek pada gambar sampel tersebut adalah gelang } \\
\text { dengan bentuk lingkaran yang terbuat dari karet } \\
\text { dan memiliki motif teks yang menjadi target poin. }\end{array}$ & 130 & 27,8 & $\sqrt{ }$ \\
\hline 8. & & $\begin{array}{l}\text { Objek pada gambar sampel tersebut adalah plat } \\
\text { nomor dan memiliki bentuk persegi panjang, } \\
\text { bahan dari stainless dan memiliki dua warna yaitu } \\
\text { hitam dan abu-abu. }\end{array}$ & 173 & 29,2 & $\sqrt{ }$ \\
\hline 9. & & $\begin{array}{l}\text { Objek gambar sampel tersebut adalah jam tangan } \\
\text { dengan dan bahan dari karet dan memiliki banyak } \\
\text { lekukan serta motif yang bervariasi. }\end{array}$ & 239 & 32,0 & $\sqrt{ }$ \\
\hline 10. & & $\begin{array}{l}\text { Objek pada gambar sampel tersebut adalah } \\
\text { kunci,bahan dari besi dan hanya memiliki satu } \\
\text { warna dan motif yang bervariasi. }\end{array}$ & 67 & 23,5 & - \\
\hline 11. & & $\begin{array}{l}\text { Objek pada gambar sampel tersebut adalah manik- } \\
\text { manik dengan bahan dari stainless memiliki variasi } \\
\text { warna dan motif yang bervariasi. }\end{array}$ & 262 & 24,3 & - . \\
\hline 12. & & $\begin{array}{l}\text { Objek pada gambar sampel tersebut adalah kartu } \\
\text { sim dengan bahan yang terbuat dari art paper dan } \\
\text { memiliki variasi warna. }\end{array}$ & 19 & 19,5 & - \\
\hline 13. & $\Leftrightarrow$ & $\begin{array}{l}\text { Objek pada gambar sampel tersebut adalah baut } \\
\text { dengan bahan yang terbuat dari besi dan memiliki } \\
\text { satu warna serta mempunyai tekukan. }\end{array}$ & 47 & 25,7 & - \\
\hline 14. & $\theta$ & Objek sampel 14 adalah beras. & 0 & 0 & - \\
\hline 15. & (6) & $\begin{array}{l}\text { Objek pada gambar tersebut adalah kancing baju } \\
\text { yang berbentuk lingkaran dan hanya memilik satu } \\
\text { warna. }\end{array}$ & 7 & 1,9 & - \\
\hline 16. & & Objek sampel 16 adalah beras. & 2 & 2,20 & - \\
\hline
\end{tabular}


Journal of Computer System and Informatics (JoSYC)

Volume 2, No. 4, August 2021, Page 304-309

ISSN 2714-8912 (media online)

ISSN 2714-7150 (media cetak)

DOI 10.47065/josyc.v2i4.826

\begin{tabular}{|c|c|c|c|c|c|}
\hline No. & Sampel & Karakteristik & $\begin{array}{c}\text { Poin } \\
\text { Scanner }\end{array}$ & $\begin{array}{l}\text { Size } \\
(\mathrm{MB})\end{array}$ & $\begin{array}{c}\text { Hasil } \\
\text { Deteksi } \\
\text { Scanner }\end{array}$ \\
\hline 17. & - & $\begin{array}{l}\text { Objek pada gambar tersebut adalah kacang hijau } \\
\text { dengan bentuk lingkaran. }\end{array}$ & 40 & 28,4 & - \\
\hline 18. & 1 & $\begin{array}{l}\text { Objek pada gambar tersebut adalah kacang merah } \\
\text { dengan bentuk bulat panjang }\end{array}$ & 7 & 8,6 & - \\
\hline
\end{tabular}

Tabel 3. Spesifikasi Handphone

\begin{tabular}{|c|c|}
\hline Spesifikasi & Asus Zenfone Max Pro M1 \\
\hline Layar & 6 inci, $2.16 \times 1.080$ piksel, Aspec ratio 18:9 \\
\hline OS & Android 8.1 (Oreo), Upgradable to Android 9.0 (Pie) \\
\hline $\mathrm{CPU}$ & Octa-core $1.8 \mathrm{GHz}$ Kryo 260 \\
\hline GPU & Adreno 509 \\
\hline RAM & $3 \mathrm{~GB}$ \\
\hline ROM & $32 \mathrm{~GB}$ \\
\hline Kamera Utama & $13 \mathrm{MP}, \mathrm{f} / 2.2,25 \mathrm{~mm}$ (wide), $1.12 \mathrm{um}, \mathrm{PDAF}+5 \mathrm{MP}$ \\
\hline Kamera Depan & $8 \mathrm{MP}, \mathrm{f} / 2.2,26 \mathrm{~mm}$ (wide) \\
\hline Face Unlock & Ada \\
\hline Fingerprint Scanner & Ada \\
\hline Baterai & Non-removable Li-Po 5000 mAh battery \\
\hline Dimensi & $159 \times 76 \times 8.5 \mathrm{~mm}$ \\
\hline
\end{tabular}

\subsection{Proses Deteksi Poin Sampel Marker Objek 3D}

Setiap sampel marker akan dilakukan pendektesian untuk mendapatkan jumlah poin dan mendapatkan titik pendektesian yang menutupi keseluruhan objek yang berdasarkan library vuforia developer, banyaknya jumlah poin tidak berpengaruh terhadap proses deteksi objek 3D yang dijadikan marker. Setiap sampel objek akan dilakukan deteksi poin menggunakan aplikasi vuforia object scanner dan juga dilengkapi dengan kertas deteksi agar proses deteksi objek dapat dilakukan. Setelah itu hasil scan tersebut akan diupload pada vuforia developer untuk dijadikan database.

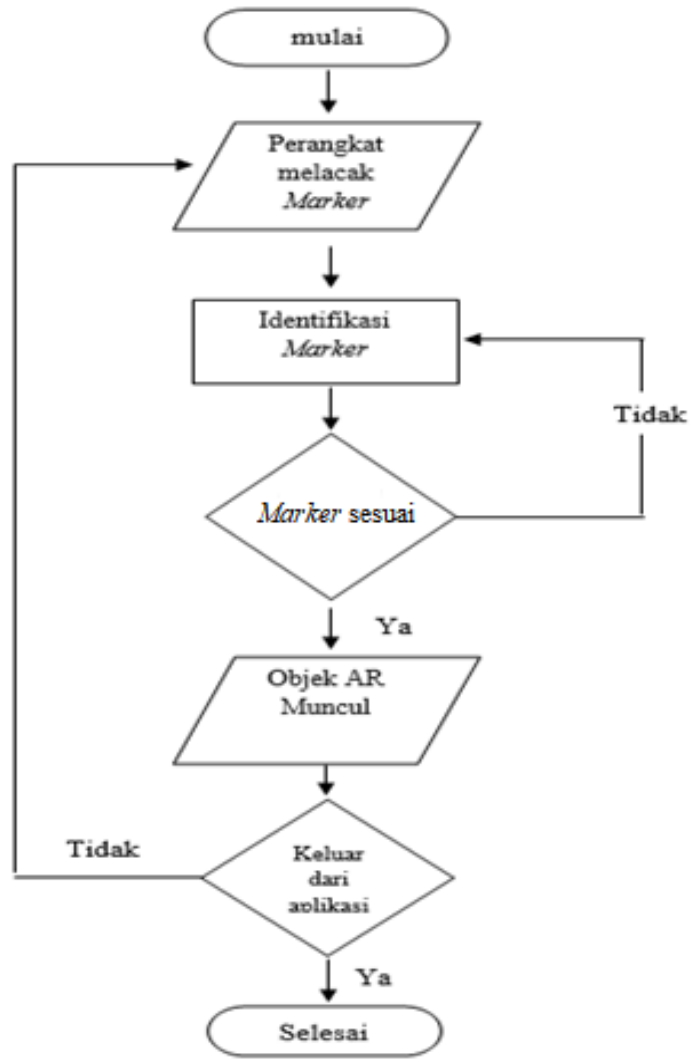

Gambar 2. Alur Deteksi Marker 


\section{HASIL DAN PEMBAHASAN}

\subsection{Analisis Hasil Pengujian Tekstur}

Dari data yang diperoleh, maka didapatkan hasil grafik untuk perbandingan tekstur dengan masing-masing sudut.

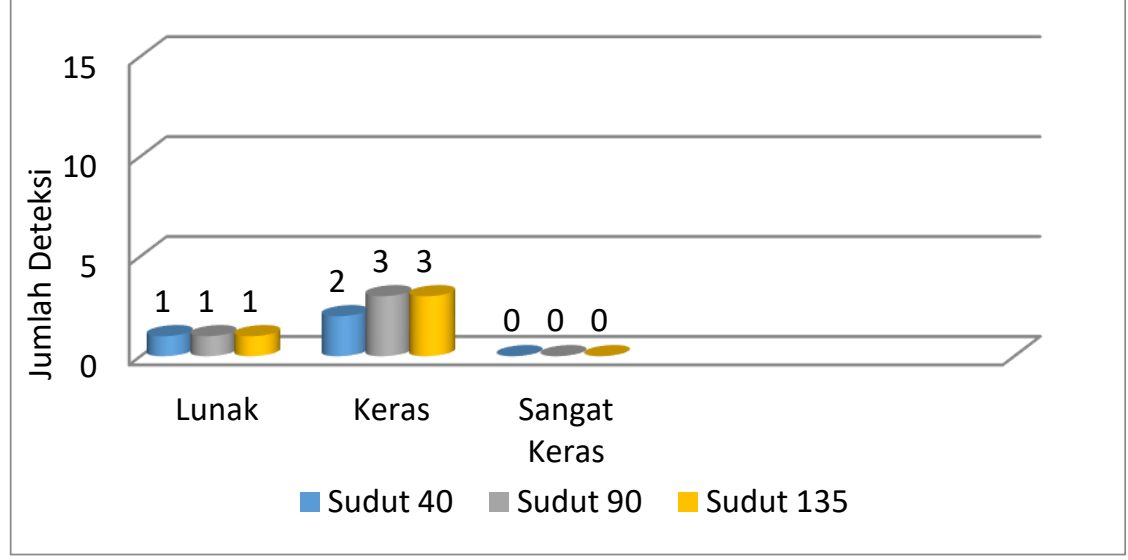

Gambar 3. Grafik Perbandingan Tekstur Dengan Masing-Masing Sudut

Gambar 3 merupakan grafik perbandingan tekstur dengan masing-masing sudut berdasarkan dari jumlah sampel marker yang dapat dideteksi, grafik tersebut memperlihatkan hasil yang diperoleh. Pada sudut $40^{\circ}$ dengan kondisi tekstur lunak didapat hasil satu sampel marker yang dapat dideteksi oleh kamera, dengan tekstur yang keras didapat hasil dua marker yang dapat dideteksi, sedangkan pada tekstur yang sangat keras tidak mendapatkan hasil apapun dalam pendeteksian tersebut. Pada sudut $90^{\circ}$ dan $135^{\circ}$ diperoleh hasil yang sama, yaitu dengan tekstur lunak didapat satu sampel marker yang dapat dideteksi, untuk tekstur keras mendapatkan hasil tiga marker yang dapat dideteksi, dan pada tekstur yang sangat keras tidak mendapatkan hasil apapun.

\subsection{Analisis Hasil Pengujian Pola}

Setelah membahas tentang tekstur dengan hasil pada Gambar 3, maka untuk hasil pengujian berdasarkan pola dapat dilihat pada gambar 4 .

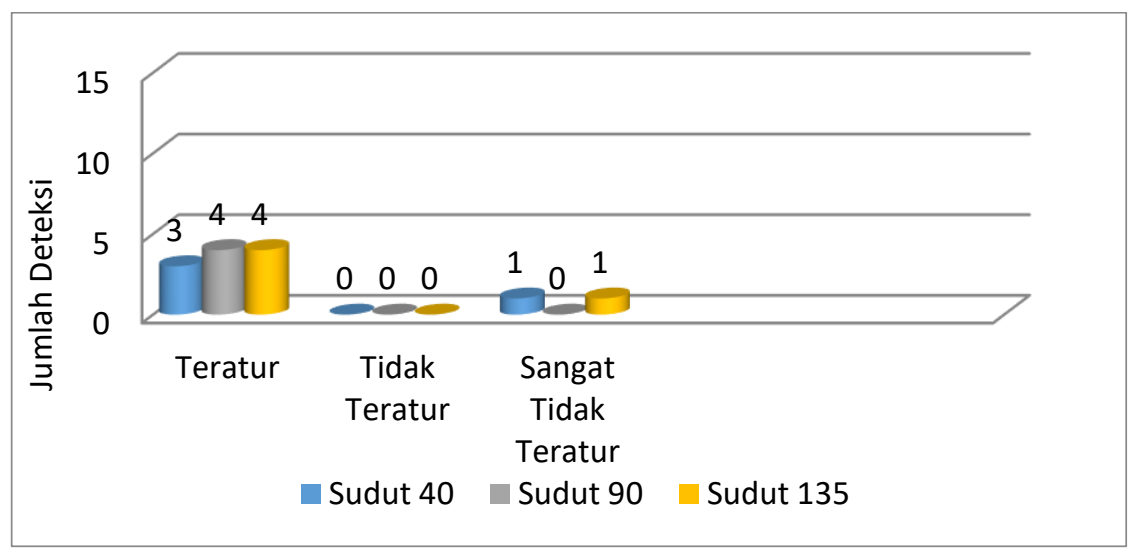

Gambar 4. Grafik Perbandingan Pola dengan Masing-Masing Sudut

Gambar 4 merupakan grafik perbandingan pola dengan masing-masing sudut, berdarkan jumlah sampel marker yang dapat dideteksi. Grafik tersebut memperlihatkan hasil yang diperoleh. Pada sudut $40^{\circ}$ dengan pola yang teratur didapat hasil tiga sampel marker yang dapat dideteksi, sedangkan untuk sampel tidak teratur tidak mendapatkan hasil apapun, dan pada pola yang sangat tidak teratur didapat satu objek 3D yang dapat dideteksi. Pada sudut $90^{\circ}$ dan $135^{\circ}$ didapatkan hasil yang sama untuk pola teratur dan tidak teratur, yaitu 4 terdeteksi pada pola teratur dan sama sekali tidak terdeteksi pada pola tidak teratur, sedangkan perbedaannya ada pada pola sangat tidak teratur yaitu tidak ada yang terdeteksi pada sudut $90^{\circ}$ dan satu terdeteksi pada sudut $135^{\circ}$.

\section{KESIMPULAN}

Berdasarkan pengujian yang telah dilakukan, didapatkan hasil bahwa jumlah poin pada vuforia object scanner tidak berpengaruh dalam pendeteksian marker, yang mempengaruhi pendeteksian marker adalah karakteristik sampel objek 3D seperti tekstur dan pola. Marker dengan kualitas yang baik untuk dijadikan sampel marker object 
Journal of Computer System and Informatics (JoSYC)

Volume 2, No. 4, August 2021, Page 304-309

ISSN 2714-8912 (media online)

ISSN 2714-7150 (media cetak)

DOI 10.47065/josyc.v2i4.826

3D adalah marker dengan tekstur yang keras, dengan posisi sudut pendeteksian $90^{\circ}$ dan $135^{\circ}$, dengan marker yang tampak realistis dengan permukaan yang mengandung satu warna serta logo dengan pola yang teratur.

\section{REFERENCES}

[1] R. T. Azuma, "A survey of augmented reality," Presence Teleoperators Virtual Environ., vol. 6, no. 4, pp. 355-385, 1997, doi: 10.1162/pres.1997.6.4.355.

[2] R. A. Setyawan and A. Dzikri, "Analisis Penggunaan Metode Marker Tracking Pada Augmented Reality Alat Musik Tradisional Jawa Tengah," Simetris J. Tek. Mesin, Elektro dan Ilmu Komput., vol. 7, no. 1, p. 295, 2016, doi: 10.24176/simet.v7i1.517.

[3] P. N. Mandarani, "Perancangan Aplikasi Promosi Teknik Informatika Berbasis Augmented Reality," in Seminar Nasional PIMIMD ITP, 2019, doi: 10.21063/PIMIMD5.2019.10.

[4] P. Mandarani, R. Yuliani, and A. Syahrani, "Pengaruh Sudut Dan Intensitas Cahaya Terhadap Kemunculan Objek 3D Pada Aplikasi Augmented Reality," Edik Inform., vol. 6, no. 2, 2020.

[5] A. Rahma and A. Syahrani, "Pengaruh Sudut Terhadap Distance dan Delay Pada Aplikasi Augmented Reality Berbasis GPS Tracking," in Seminar Nasional Aplikasi Teknologi Informasi (SNATI), 2017.

[6] P. Mandarani and N. A. Suhendri, "Pengaruh Manipulasi Nilai Kontras, Kecerahan dan Warna Gambar terhadap Rating Image Marker pada Augmented Reality," J. Teknoif, vol. 6, no. 2, pp. 120-127, 2018, doi: 10.21063/jtif.2018.v6.2.120127.

[7] Y. Turkan, R. Radkowski, A. Karabulut-Ilgu, A. H. Behzadan, and A. Chen, "Mobile augmented reality for teaching structural analysis," Adv. Eng. Informatics, vol. 34, no. October 2016, pp. 90-100, 2017, doi: 10.1016/j.aei.2017.09.005.

[8] S. S. Deshmukh, C. M. Joshi, R. S. Patel, and Y. B. Gurav, "3D Object Tracking And Manipulation In Augmented Reality .," Int. Res. J. Eng. Technol., vol. 5, no. 1, pp. 287-289, 2018.

[9] E. V. Haryanto, E. L. Lubis, A. Saleh, Fujiati, and N. I. Lubis, "Implementation of Augmented Reality of Android Based Animal Recognition using Marker Based Tracking Methods," J. Phys. Conf. Ser., vol. 1361, no. 1, 2019, doi: 10.1088/1742-6596/1361/1/012019.

[10] T. A. Vakaliuk and S. I. Pochtoviuk, "Analysis of tools for the development of augmented reality technologies," CEUR Workshop Proc., vol. 2898, pp. 119-130, 2021.

[11] R. A. Grigorev, V. B. Adhamdzon-Ugli, O. A. Medvedeva, and S. A. Mustafina, "Information system development using augmented reality tools," CEUR Workshop Proc., vol. 2525, no. figure 1, 2019. 